\title{
Evaluating the impact of a home-based rehabilitation service on older people and their caregivers: a matched-control quasi- experimental study
}

This article was published in the following Dove Press journal:

Clinical Interventions in Aging

\section{Iris Fung-Kam Lee' \\ Felix Ngok Yau ${ }^{2}$ \\ Sally Suk-Ha Yim² \\ Diana Tze-Fan Lee'}

'The Nethersole School of Nursing, The Chinese University of Hong Kong, Shatin, Hong Kong, Special Administrative Region; ${ }^{2}$ Nethersole Outreaching Rehabilitation Mission, Alice Ho Miu Ling Nethersole Charity Foundation, Hong Kong, Special Administrative Region
Correspondence: Iris Fung-Kam Lee Room 730, Esther Lee Building, The Nethersole School of Nursing, The Chinese University of Hong Kong, Shatin, New Territories, Hong Kong, Special Administrative Region

Tel +852 39436228

Fax +85226035269

Email fk95lee@cuhk.edu.hk
Introduction: Previous studies evaluating home-based rehabilitation service (HBRS) merely focused on the period immediately after the patients' discharge from hospitals. The present study focuses on HBRS that covers clients who have not been recently hospitalized. HBRS aims to meet older clients' rehabilitation needs and support their caregivers in the community. This study intended to evaluate the impact of HBRS on the older clients' health outcomes and hospital services utilization, and caregivers' strain in providing care for clients.

Methods: This study used a matched-control quasi-experimental design with a 3-month follow-up to evaluate HBRS. The health outcome measures used for the older clients included Elderly Mobility Scale, Timed Up and Go test, Modified Barthel Index, Lawton's Instrumental Activities of Daily Living Scale, Mini-Mental State Examination, and World Health Organization Quality of Life Scale, Short Form, Hong Kong version (WHOQOL-BREF [HK]). Meanwhile, the Caregiver Strain Index was used to measure the caregivers' caregiving strain. Data on clients' hospital services utilization 3 and 6 months before and after the study were also collected and evaluated.

Results: The final sample consisted of 122 pairs of older clients and caregivers who live in a community in Hong Kong. In the follow-up after 3 months, the intervention group showed immensely substantial improvements across all the health outcome measures compared with the control group. The intervention group also demonstrated substantial reduction in the clients' hospital services utilization compared with the control group. However, no significant differences in the clients' hospital services utilization exist between the two groups in the follow-up after 6 months.

Conclusion: HBRS of this study is an effective intervention service to improve health outcomes and reduce hospital services utilization among older people living in the community. Moreover, HBRS of this study was effective in reducing the caregivers' caregiving strain.

Keywords: elderly, community, Elderly Mobility Scale, Caregiver Strain Index, hospital services utilization

\section{Introduction}

Geriatric rehabilitation enables a person's autonomy and physical condition to recover, be restored, and improved, thereby allowing him to live life to the fullest. ${ }^{1}$ Rehabilitation is not a single intervention but a process that healthcare professionals assist the older people to pursue holistic health. ${ }^{2-5}$ A cohort study on orthopedic older patients suggested that home intervention significantly shortened the duration of rehabilitation and enhanced its efficiency $(P<0.01) .6$ Two pragmatic randomized controlled trials (RCTs) with similar designs, from the UK $(\mathrm{N}=250)^{7}$ and Sweden $(\mathrm{N}=205){ }^{8}$ 
suggested that community in-reach rehabilitation and care transition could reduce hospital stay for 2.3 and 6 days, respectively. Effective rehabilitation programs can enhance clients' physical functioning and mobility through tailored and individualized physical training. ${ }^{9}$ Moreover, the locations of those who deliver rehabilitation care have to match the needs of the older patients. ${ }^{4}$ Systematic reviews showed a heterogeneous impact of the location of those who provide rehabilitation care. ${ }^{3,10}$ However, another systematic review claimed that patients have demonstrated better physical function, cognition, quality of life, and higher satisfaction with home-based rehabilitation service (HBRS) compared with in-patient rehabilitation services. ${ }^{11}$ Moreover, patients were less likely to suffer deterioration or death (OR 0.76, 95\% CI 0.64-0.90) when rehabilitated at home. ${ }^{12}$ An RCT $(\mathrm{N}=40)$ of home-based cardiac rehabilitation for older clients showed that home visits by a physiotherapist combined with individualized exercise substantially improved the clients' exercise capability. ${ }^{13}$ Accordingly, the clients were considerably willing to participate in the rehabilitation process with strong self-efficacy. ${ }^{14}$ However, previous studies have merely evaluated the outcomes immediately after the patients' discharge from hospitals. The findings of previous studies on the impact of the rehabilitation location on the caregiver were inconsistent. ${ }^{15-17}$ An RCT by Crotty et $\mathrm{al}^{15}$ indicated that the caregivers' stress level was significantly lower in the homebased group compared with that in the day hospital group at discharge. However, no substantial difference was observed between the two groups in the follow-up after 3 months. Similarly, Anderson et $\mathrm{al}^{16}$ determined that the caregivers' mental well-being was significantly lower in the homebased group in the follow-up after 6 months compared with conventional care and rehabilitation in the hospital. Another RCT showed that the caregivers' psychological well-being was unaffected by the rehabilitation location. ${ }^{17}$ Arguably, the effects on caregivers were likely to be affected by the home-based intervention support. ${ }^{16}$

The HBRS evaluated in this study is a nonprofit making community rehabilitation service that receives referrals from various sources, including hospitals, community services, outpatient departments/clinics, and general practitioners in the community, for the provision of rehabilitation service at the client's home. These referrals are not necessarily for clients who are immediately discharged from hospitals. The major characteristics of HBRS are as follows. First, HBRS providers have an office in the district hospital of its catchment area and they are appointed by that hospital as honorary staff members, thereby enabling them to access the client's medical records and communicate closely with hospital staff members to promote the client's rehabilitation. Second, HBRS also establishes close connections with community health and social services providers to assist the client to live independently at home. Third, HBRS adopts a person-centered care approach, in which the therapist provides professional advice, while the client identifies personal goals in the rehabilitation process. With respect to the client's preferences, the therapist has the professional autonomy to schedule home visits to provide tailor-made services that will address the former's individual needs. Moreover, the therapist also supports the family caregiver by providing caregiving knowledge and teaching skills pertinent to the client's health condition. Fourth, networks of the HBRS therapists across hospitals and the community will enable them to act similar to case managers who can refer clients or caregivers to the appropriate health or social resources. Compared with Mas et al, ${ }^{6}$ Sahota et al, ${ }^{7}$ and Karlsson et al, ${ }^{8}$ the current study's HBRS covers clients who have not been recently hospitalized and includes a larger range of clients who suffer from various health conditions, such as cardiovascular diseases, musculoskeletal problems, neurological problems, respiratory problems, cancers, and falls.

The present study aimed to evaluate the impact of HBRS in terms of older clients' health outcomes and hospital services utilization, as well as caregivers' strain in providing care for clients.

\section{Methods Design}

This study used a matched-control quasi-experimental study design that consists of a baseline and follow-up survey after 3 months.

\section{Subjects}

The intervention group subjects were recruited from clients who were newly referred to HBRS. Accordingly, HBRS accepts referral from a registered healthcare professional, who is in charge of the client and is practicing within the district it serves. For example, medical officers of outpatient clinics, general practitioners, and registered nurses may refer clients to HBRS. Meanwhile, the control group subjects were recruited from two integrated home care service teams and two community social centers for older people in the same HBRS district. The client inclusion criteria for both groups are as follows: 1) $\geq 60$ years old; 2) cognitively intact as indicated by a score of $\geq 22$ in the Mini-Mental State Examination (MMSE) or a score of $\geq 18$ for those who 
are illiterate; ${ }^{18} 3$ ) supported by a caregiver (who provides daily direct care to the client); 4) living at home; and 5) can communicate verbally. Apart from the inclusion criteria, five criteria were used to match the control group with the intervention group: 1) gender of the client; 2) age of the client ( \pm 10 years); 3 ) disease type of the client; and 4 ) frailty level of the client as validated by the Clinical Frailty Scale (CFS) $\left( \pm 1\right.$ level). ${ }^{19,20}$

The results of a previous study on patients' mobility ${ }^{21}$ indicated that an effect size of 0.5 was used to estimate the sample size. A sample size of 64 pairs of older clients and caregivers per group is needed for a two-sided hypothesis test using an independent sample $t$-test or one-way betweengroups ANOVA with a type 1 error of $5 \%$ and power of $80 \% .^{22}$

\section{Intervention vs control}

The intervention group clients were provided with a homebased one-on-one rehabilitation program supported by experienced and registered physiotherapists, occupational therapists, and rehabilitation assistants. The duration of rehabilitation was not standardized but depended on the client's progress, which is often within 3-6 months at 45 minutes per session. Individualized therapy sessions involved physiotherapy or occupational therapy such as various types of exercise training (eg, muscle strengthening and balance exercise), mobility training, training on basic and instrumental activities of daily living, pain relief therapy, chest physiotherapy, rehabilitation aids prescription and training, home safety assessment and modification, and cognitive and memory training. Apart from the training given to the client, caregivers were also provided education and skills training. The payment for each therapy session was USD10. The first HBRS visit to the client at home was scheduled within 10 days (or 3 days for urgent cases) after referral. In the course of rehabilitation, the HBRS staff members could make necessary referrals for the client or caregiver to a hospital department or a community service center. The control group clients did not receive HBRS or any other active rehabilitation service.

\section{Questionnaire}

Baseline demographic data were collected from the clients and caregivers. The health services utilization of the client, including numbers of Accident and Emergency Department (AED) attendance, unplanned hospital admissions, and bed days were retrieved from their medical records 3 and 6 months before and after the study, respectively. A baseline survey was carried out via the validated scales within 5 days before HBRS for the intervention group and within 5 days from the recruitment day for the control group. A follow-up survey using the same scales was performed after 3 months. Data collection was conducted via face-to-face interviews with the clients and their caregivers by a trained research assistant (RA) of this study.

\section{Client's mobility}

The 7-item Elderly Mobility Scale (EMS) was used to assess the client's level of mobility; EMS has been validated among the older Chinese population in Hong Kong. ${ }^{23,24}$ The possible scores range from 0 to 20, in which a higher score indicates a higher level of independence in mobility. The Timed Up and Go (TUG) test, which has a high interrater reliability (intraclass correlation $>0.9$ ) and satisfactory validity, ${ }^{25,26}$ was used to assess the client's ambulatory ability. TUG involves a measurement of the time in seconds. The client, who wears regular footwear and uses customary walking aid, is asked to stand up from sitting on a standard arm chair, walk $3 \mathrm{~m}$, turn, walk back to the chair, and sit down. Lesser time represents a better ambulatory ability.

\section{Physical functioning}

The Chinese version of the 10-item Modified Barthel Index (MBI) was used to assess the client's physical functioning in terms of personal hygiene, bathing, feeding, toileting, stair climbing, dressing, bowel control, bladder control, ambulation, or wheelchair and chair-bed transfer. Accordingly, a higher score indicates a higher level of independence in the physical activities. ${ }^{27}$ The Chinese version of MBI, which has scores ranging from 0 to 100 , was shown to have good internal consistency (Cronbach's alpha $=0.93$ ) ${ }^{28}$ The Chinese version of Lawton's Instrumental Activities of Daily Living Scale (IADL) consists of eight items: taking medication, meal preparation, phone use, laundry, ordinary housework, managing finances, shopping, and transportation. This version was used to assess the client's instrumental activities of daily living and was validated among the Hong Kong older people. ${ }^{29,30}$ Lawton's IADL score was computed based on the eight items using a 3 -point scale $(0,1$, and 2$)$. The scores range from 0 to 16 , with a higher score representing a higher level of independence in performing instrumental activities.

\section{Cognitive status}

The Cantonese version of the 11-item MMSE was used to measure the client's cognitive ability. The possible scores 
ranged from 0 to 30 , with a higher score indicating a better cognitive status. ${ }^{31}$ The Cantonese version of MMSE showed good reliability (Cronbach's alpha=0.86) and validity among the Hong Kong elders. ${ }^{31}$

\section{Quality of life}

The Hong Kong-Chinese version of the 28-item WHO Quality-of-Life Scale (WHOQOL-BREF) was used to assess the clients' subjective report on their quality of life and health in the last 2 weeks. ${ }^{32}$ WHOQOL-BREF has acceptable psychometric properties with Cronbach's alpha coefficients ranging from 0.67 to 0.79 and test-retest reliability coefficients ranging from 0.64 to $0.90 .{ }^{33}$ Each item is rated on a 5-point Likert scale and a higher score indicates a higher level of quality of life. The 28 items include an item on overall quality of life (score range 1-5), another on the overall health (score range 1-5), and the remaining 26 items are grouped into four domains (ie, physical, psychological, social, and environmental health). Each of the domain and scale (total) scores were transformed into $0-100$, in accordance with the scale manual.

\section{Caregiver's strain}

The caregiver's caregiving strain was measured using the Chinese version of the 13-item Caregiver Strain Index (CSI), which has been validated in a group of Chinese caregivers $(\mathrm{N}=223)$ with Cronbach's alpha $=0.91 .{ }^{34}$ The items require a yes or no response. The possible scores range from 0 to 13 , with a higher score indicating a higher level of caregiving strain.

\section{Statistical analysis}

The SPSS version 24.0 (IBM Corporation, Armonk, NY, USA) was used for data analysis. The characteristics at baseline were compared using either the $t$-test or chi-square test. One-way between-groups ANCOVA was used to compare the outcome measures between the intervention and control groups with adjustments for the potential confounding variables. All statistical tests were two-sided and a $P$-value $<0.05$ was considered statistically significant.

\section{Ethical considerations}

This study was approved by the Joint Chinese University of Hong Kong - New Territories East Cluster Clinical Ethics Research Committee, The Chinese University of Hong Kong, and the Hong Kong's Hospital Authority. Moreover, informed written consents were obtained from the participants before the implementation of the study. The RA explained the objectives and the voluntary nature of the study to the participants, who were given time to ask questions.

\section{Results}

The final sample comprised 122 pairs of clients and caregivers, with 61 pairs each in the intervention group and the control group. Between September 1, 2015 and September $30,2016,80$ pairs of eligible clients and caregivers in the intervention group and 91 pairs in the control group agreed to participate in the study (Figure 1). In the intervention group, five clients $(6.3 \%)$ passed away, one pair of client and caregiver (1.3\%) lost contact, and one pair (1.3\%) refused follow-up. Hence, a $8.9 \%$ attrition rate was recorded. Among the remaining 71 pairs of clients and caregivers in the intervention group, 10 pairs (14.1\%) were unable to match with a pair of the control group, thereby leaving a total of 61 pairs $(85.9 \%)$ for the final analysis. In the control group, two clients $(2.0 \%)$ passed away, seven pairs of clients and caregivers $(6.8 \%)$ missed the follow-up and eleven pairs of clients and caregivers (10.8\%) refused follow-up; hence, there was a $19.6 \%$ attrition rate. Among 82 pairs of clients and caregivers in the control group, 21 pairs $(25.6 \%)$ were unable to match with a pair in the intervention group, thereby leaving a total of 61 pairs $(74.4 \%)$ for the final analysis.

Tables 1 and 2 show the baseline characteristics of the participants. No significant differences in terms of age, gender, disease group, and marital status were observed between the clients in the two groups. However, clients in the intervention group were frailer and had a higher educational level compared with those in the control group. Meanwhile, no significant differences in terms of marital and employment statuses were observed between the caregivers in the two groups. However, those in the intervention group were significantly younger and more educated. Moreover, the majority of them were females.

The frequency of the HBRS therapy sessions provided to the intervention group ranged from 2 to 26 sessions with a mean frequency of $8.52(\mathrm{SD}=4.65)$ in the period from baseline survey to the follow-up survey after 3 months. The median and mode frequencies were 7 and 6 . The majority of the clients $(\mathrm{N}=42 ; 69 \%)$ received $6-10$ therapy sessions. The variability in the number of therapy sessions was influenced by the clients' rehabilitation needs and physical tolerance. For example, clients with greater impairment may receive more therapy sessions owing to the higher need for rehabilitation training, whereas frail clients might receive fewer sessions because of lower physical tolerance for rehabilitation training. Clients would have two sessions if they only required 


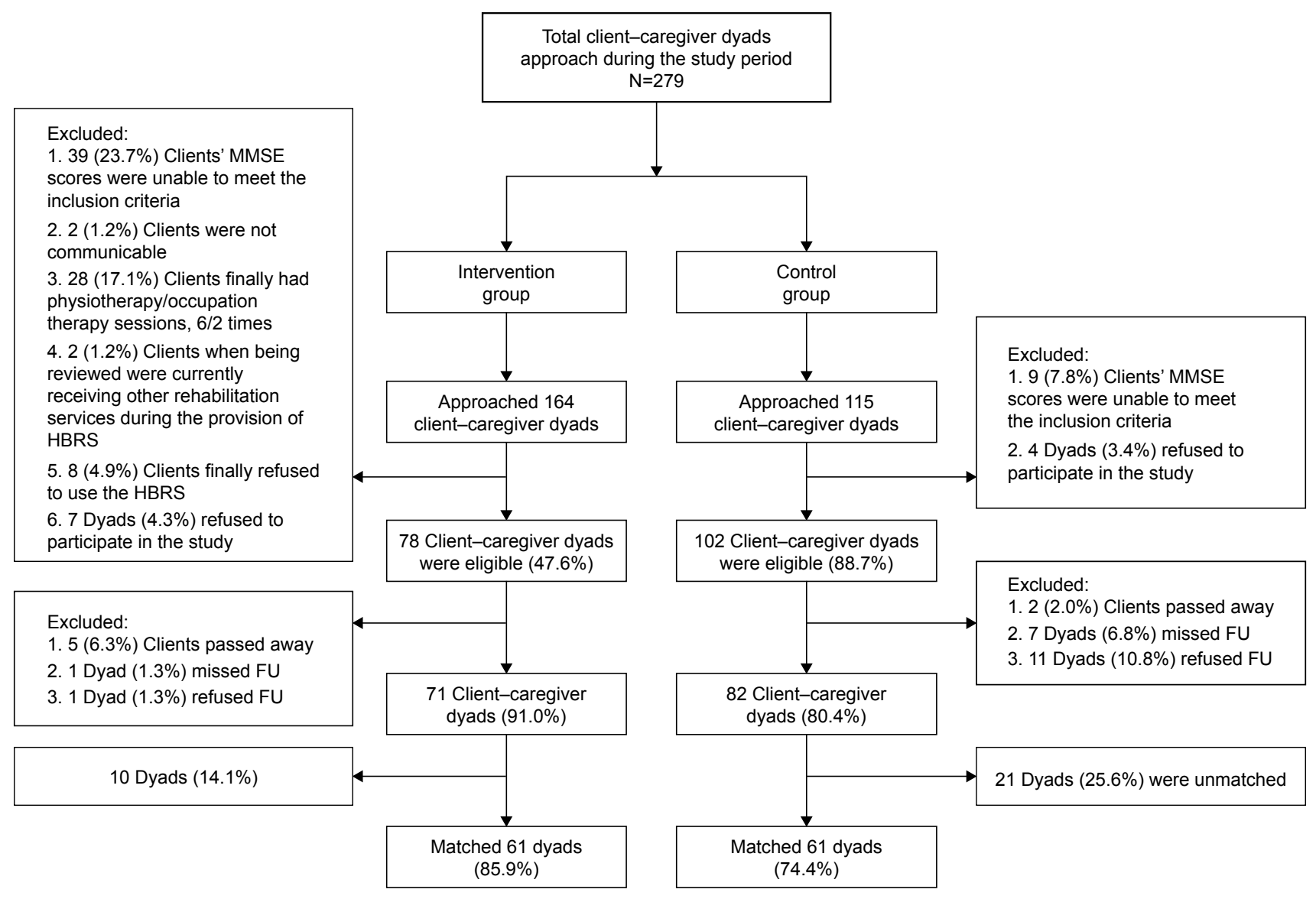

Figure I The flow of participants in the study.

Abbreviations: MMSE, Mini-Mental State Examination; HBRS, home-based rehabilitation service; FU, follow-up.

home modification service. In addition, caregivers with a higher ability in assisting the client for rehabilitation training may reduce the number of therapy sessions.

\section{Health outcomes}

Table 3 shows the results of the health outcomes after 3 months. The one-way between-groups ANCOVA was used to compare the posttests of the clients' health outcomes and control for the respective baseline dependent variable, frailty (ie, CFS score), and educational levels owing to the variation between the two groups. Compared with the control group, the intervention group demonstrated significantly higher adjusted mean scores in mobility (ie, EMS posttest), physical activities of daily living (ie, MBI posttest), instrumental activities of daily living (ie, Lawton's IADL posttest), cognitive functioning (ie, MMSE posttest), and the overall quality of life (ie, WHOQOL-BREF [HK] posttests), which includes physical, psychological, social, and environmental aspects. In addition, the intervention group also showed a significantly greater improvement in ambulation ability (ie, TUG posttest) with lesser time spent in completing the test.
The clients' improvements in mobility, physical activities of daily living, and instrumental activities of daily living were $24.2 \%, 16.0 \%$, and $19.3 \%$, respectively. We also used ANCOVA to compare the caregivers' caregiving strain (ie, CSI posttest) and control for the baseline CSI, age, gender, and educational level. The intervention group's caregiving strain was significantly lower than that of the control group. Cohen's guidelines indicated that the values of partial etasquare for small, moderate, and large effects were 0.01 , 0.06 , and 0.14 , respectively. ${ }^{22}$ Hence, the HBRS of this study demonstrated considerable effects on improving the clients' mobility, physical, and cognitive functioning, as well as their overall quality of life. HBRS also demonstrated a moderate effect on the reduction of caregivers' caregiving strain.

Table 4 shows the comparison results of hospital services utilization between the intervention and control groups. We used ANCOVA to compare the AED attendance, number of unplanned hospital admissions, and bed days and control for the client's frailty (ie, CFS score) and educational levels owing to the variation between the two groups. The results of the follow-up after 3 months showed that the intervention group 
Table I Clients characteristics between the intervention and the matched-control groups

\begin{tabular}{|c|c|c|c|c|}
\hline \multirow[t]{3}{*}{ Characteristics } & \multirow{2}{*}{$\begin{array}{l}\text { Intervention } \\
\text { group }(\mathrm{N}=6 \mathrm{I}) \\
\text { Mean }(\mathrm{SD}) \text { range }\end{array}$} & \multirow{2}{*}{$\begin{array}{l}\text { Matched-control } \\
\text { group }(\mathrm{N}=6 \mathrm{I}) \\
\text { Mean }(\mathrm{SD}) \text { range }\end{array}$} & \multirow[t]{2}{*}{$\boldsymbol{t}$} & \multirow[t]{3}{*}{$\begin{array}{l}\text { P-value } \\
\text { (two-sided) }\end{array}$} \\
\hline & & & & \\
\hline & $\mathbf{N}(\%)$ & $\mathbf{N}(\%)$ & $\chi^{2}$ & \\
\hline \multirow[t]{2}{*}{ Age (years) } & $77.69(8.15)$ & $77.92(6.5 I)$ & -0.172 & 0.864 \\
\hline & $60-93$ & $63-93$ & & \\
\hline \multicolumn{5}{|l|}{ Gender } \\
\hline Male & $19(31.1)$ & $19(31.1)$ & 0.000 & 1.000 \\
\hline Female & $42(68.9)$ & $42(68.9)$ & & \\
\hline \multicolumn{5}{|l|}{ Disease group } \\
\hline Cardiovascular & $24(39.3)$ & $24(39.3)$ & 0.000 & 1.000 \\
\hline Musculoskeletal & $20(32.8)$ & $20(32.8)$ & & \\
\hline Neurological & $8(13.1)$ & $8(13.1)$ & & \\
\hline Fall & $6(9.8)$ & $6(9.8)$ & & \\
\hline Pulmonary & $2(3.3)$ & $2(3.3)$ & & \\
\hline Cancer & I (I.6) & I (I.6) & & \\
\hline \multicolumn{5}{|l|}{ Clinical Frailty Scale } \\
\hline Managing well ${ }^{\mathrm{MI}}$ & $0(0)$ & $2(3.3)$ & 18.698 & $<0.001$ \\
\hline$V_{\text {Vulnerable }}^{M I}$ & $6(9.8)$ & $20(32.8)$ & & \\
\hline Mildly frail & $20(32.8)$ & $25(4 I .0)$ & & \\
\hline Moderately frail ${ }^{\mathrm{M2}}$ & $35(57.4)$ & $14(23.0)$ & & \\
\hline Severely frail ${ }^{\mathrm{M} 2}$ & $0(0)$ & $0(0)$ & & \\
\hline \multicolumn{5}{|l|}{ Marital status } \\
\hline Married & $37(60.7)$ & 39 (63.9) & 0.035 & 0.852 \\
\hline Single $\mathrm{a}^{\mathrm{a}}$ & I (I.6) & $0(0)$ & & \\
\hline Divorced/separate ${ }^{\mathrm{a}}$ & $5(8.2)$ & $2(3.3)$ & & \\
\hline Widowed ${ }^{\mathrm{a}}$ & $18(29.5)$ & $20(32.8)$ & & \\
\hline \multicolumn{5}{|l|}{ Educational level (\%) } \\
\hline No formal education & $24(39.3)$ & $21(34.4)$ & 6.209 & 0.045 \\
\hline Primary level & $20(32.8)$ & $32(52.5)$ & & \\
\hline Secondary level ${ }^{a}$ & $13(21.3)$ & $7(11.5)$ & & \\
\hline Tertiary level or above ${ }^{a}$ & $4(6.6)$ & I (I.6) & & \\
\hline
\end{tabular}

Notes: Merge of categories cannot meet the need of two different merges in the categories of Clinical Frailty Scale. The two categories of MI have been merged as one category and the two categories of $\mathrm{M} 2$ have been merged as another category for data analysis.

had substantially reduced the AED attendance, unplanned hospital admissions, and bed days compared with those of the control group. Hence, HBRS demonstrated moderate to large effects on the reduction of hospital services utilization in the follow-up after 3 months. However, no significant differences between the two groups in any of the hospital services utilization were reported in the follow-up after 6 months.

\section{Discussion}

This study investigated the effectiveness of a community HBRS, which has the unique characteristics of close connections between the staff members of the hospital and community services and access rights to clients' medical records. Moreover, therapists and clients mutually agreed to a treatment plan and the use of a case management approach. HBRS is considered a tailor-made community rehabilitation service delivered to older clients and their caregivers at home. The results showed that HBRS significantly enhanced the clients' mobility, physical functioning, cognitive functioning, and overall quality of life. HBRS also reduced the clients' hospital services utilization in terms of AED attendance, unplanned hospital admissions, and length of hospital stay. These positive findings are consistent with the findings of previous home-based geriatric rehabilitation studies. ${ }^{6-8,34}$

In the present study, more emphasis was placed on assessing the clients' mobility, which was an essential predictive factor to their living at home independently after geriatric rehabilitation (as supported by a prospective cohort study). ${ }^{35}$ This study reported an increase of the mobility score (ie, EMS) from a mean score of 10.95 to 14.82 in the intervention group. This result reflects an improvement of the clients' mobility from a borderline level of independence to an independent level in the home setting within 3 months. ${ }^{18}$ This positive result is consistent with the result of a systematic review that supported home-based multidisciplinary rehabilitation. The review indicated that HBRS results in substantial 
Table 2 Caregiver characteristics: comparison between the intervention and matched-control groups

\begin{tabular}{|c|c|c|c|c|}
\hline \multirow[t]{3}{*}{ Characteristics } & \multirow{2}{*}{$\begin{array}{l}\text { Intervention } \\
\text { group }(\mathrm{N}=6 \mathrm{I}) \\
\text { Mean (SD) range }\end{array}$} & $\begin{array}{l}\text { Matched-control } \\
\text { group }(\mathrm{N}=6 \mathrm{I})\end{array}$ & \multirow[t]{2}{*}{$\boldsymbol{t}$} & \multirow[t]{3}{*}{$\begin{array}{l}P \text {-value } \\
\text { (two-sided) }\end{array}$} \\
\hline & & Mean (SD) range & & \\
\hline & $\mathbf{N}(\%)$ & $\mathbf{N}(\%)$ & $x^{2}$ & \\
\hline \multirow[t]{2}{*}{ Age (years) } & $57.52(14.55)$ & $65.77(17.22)$ & -2.857 & 0.005 \\
\hline & $25-84$ & $25-90$ & & \\
\hline \multicolumn{5}{|l|}{ Gender } \\
\hline Male & I5 (24.6) & $29(47.5)$ & 6.008 & 0.014 \\
\hline Female & $46(75.4)$ & $32(52.5)$ & & \\
\hline \multicolumn{5}{|l|}{ Marital status } \\
\hline Married & $48(78.7)$ & $56(91.8)$ & 3.193 & 0.074 \\
\hline Single $\mathrm{e}^{\mathrm{a}}$ & II (I8.0) & $4(6.6)$ & & \\
\hline Divorced/separate ${ }^{a}$ & $2(3.3)$ & I (I.6) & & \\
\hline \multicolumn{5}{|l|}{ Educational level } \\
\hline No formal education & $3(4.9)$ & II (I8.0) & 10.927 & 0.012 \\
\hline Primary level & $14(23.0)$ & $20(32.8)$ & & \\
\hline Secondary level & $29(47.5)$ & $25(4 \mid .0)$ & & \\
\hline Tertiary level or above & $15(24.6)$ & $5(8.2)$ & & \\
\hline \multicolumn{5}{|l|}{ Employment } \\
\hline Part time & $16(26.3)$ & $15(24.6)$ & 0.000 & 1.000 \\
\hline Unemployed & $45(73.7)$ & $46(75.4)$ & & \\
\hline
\end{tabular}

Notes: aMerge of categories for the chi-square test; percentages may not add up to $100 \%$ owing to rounding off.

improvements in balance confidence, functional status, and lower extremity muscle strength compared with no rehabilitation at all. ${ }^{36}$ However, a previous RCT suggested that the gain of rehabilitation effects may not be maintained at 12 months. ${ }^{34}$
Thus, the recommendation is to lengthen the time frame for this outcome measure in future studies. In addition, the minimal clinically important difference (MCID) for EMS was identified as 2 points (10\% of the scale). ${ }^{37}$ The results of

Table 3 Comparisons of the posttests of health outcome measures between the intervention and matched-control groups at 3-month follow-up by one-way between-groups ANCOVA

\begin{tabular}{|c|c|c|c|c|c|c|c|}
\hline \multirow[t]{2}{*}{ Outcomes } & \multicolumn{2}{|l|}{ Baseline } & \multicolumn{2}{|l|}{ 3-month follow-up } & \multirow[t]{2}{*}{$F^{a}$} & \multirow[t]{2}{*}{$P$-value } & \multirow{2}{*}{$\begin{array}{l}\text { Partial } \\
\text { eta-square }\end{array}$} \\
\hline & $\begin{array}{l}\text { Intervention } \\
(\mathrm{N}=61)\end{array}$ & $\begin{array}{l}\text { Matched-control } \\
(\mathrm{N}=6 \mathrm{I})\end{array}$ & $\begin{array}{l}\text { Intervention } \\
(\mathrm{N}=6 \mathrm{I})\end{array}$ & $\begin{array}{l}\text { Matched-control } \\
(\mathrm{N}=61)\end{array}$ & & & \\
\hline $\mathrm{EMS}^{\mathrm{b}}$ & $10.95 \pm 4.85$ & $14.82 \pm 4.10$ & $14.75\left(16.33^{\mathrm{c}}\right) \pm 4.75$ & $15.69\left(14.12^{c}\right) \pm 4.18$ & 16.178 & $<0.001$ & 0.121 \\
\hline TUG $^{d}$ & $38.02 \pm 22.92$ & $23.11 \pm 19.19$ & $23.10\left(18.37^{c}\right) \pm 14.89$ & $23.93\left(27.39^{c}\right) \pm 13.37$ & 13.517 & $<0.001$ & 0.128 \\
\hline $\mathrm{MBl}^{\mathrm{e}}$ & $66.16 \pm|5.8|$ & $80.07 \pm 13.26$ & $82.16\left(87.88^{c}\right) \pm 16.23$ & $79.36\left(73.64^{c}\right) \pm 15.32$ & 47.526 & $<0.001$ & 0.289 \\
\hline Lawton's IADL ${ }^{f}$ & $7.18 \pm 2.30$ & $9.59 \pm 2.88$ & $10.26\left(11.38^{c}\right) \pm 2.39$ & $10.38\left(9.26^{c}\right) \pm 3.59$ & 26.666 & $<0.001$ & 0.186 \\
\hline MMSEg & $25.02 \pm 3.21$ & $25.66 \pm 3.12$ & $26.41\left(26.65^{c}\right) \pm 2.84$ & $24.25\left(24.0 I^{c}\right) \pm 4.19$ & 23.903 & $<0.001$ & 0.170 \\
\hline WHOQOL-BREF $(\mathrm{HK})^{\mathrm{h}}$ & $61.88 \pm 11.58$ & $67.30 \pm 14.07$ & $71.61\left(73.53^{c}\right) \pm 12.85$ & $68.17\left(66.28^{c}\right) \pm 9.91$ & 13.358 & $<0.001$ & 0.103 \\
\hline - QOL in general & $3.38 \pm 1.03$ & $3.56 \pm 0.92$ & $3.70\left(3.72^{\mathrm{c}}\right) \pm 1.0 \mathrm{I}$ & $3.61\left(3.58^{c}\right) \pm 0.80$ & 0.602 & 0.439 & 0.005 \\
\hline - General healthi & $2.87 \pm 1.16$ & $3.5 \mathrm{I} \pm 1.03$ & $3.27\left(3.43^{c}\right) \pm 1.39$ & $3.13\left(2.98^{c}\right) \pm 1.13$ & 3.373 & 0.069 & 0.028 \\
\hline - Physical health domain ${ }^{h}$ & $41.10 \pm 16.75$ & $54.13 \pm 20.74$ & $55.78\left(60.59^{c}\right) \pm 20.01$ & $56.38\left(51.65^{c}\right) \pm 17.69$ & 8.050 & 0.005 & 0.065 \\
\hline - Psychological health domain ${ }^{\mathrm{h}}$ & $55.28 \pm \mid 7.21$ & $62.28 \pm 21.04$ & $66.50\left(68.60^{c}\right) \pm 20.51$ & $62.39\left(60.33^{c}\right) \pm 13.86$ & 6.640 & 0.011 & 0.054 \\
\hline - Social relationship domain ${ }^{\mathrm{h}}$ & $61.98 \pm 15.50$ & $62.26 \pm 14.19$ & $68.60\left(69.25^{c}\right) \pm|5.5|$ & $63.18\left(62.54^{c}\right) \pm 14.10$ & 5.422 & 0.022 & 0.045 \\
\hline - Environment domain ${ }^{\mathrm{h}}$ & $57.92 \pm 16.06$ & $61.49 \pm 18.15$ & $70.78\left(72.36^{c}\right) \pm 14.82$ & $63.16\left(61.62^{c}\right) \pm 12.47$ & 19.37 & $<0.001$ & 0.143 \\
\hline $\mathrm{CSI}^{\mathrm{i}}$ & $6.68 \pm 1.37$ & $5.70 \pm 1.53$ & $4.18(3.49 c) \pm 3.75$ & $4.38\left(5.06^{\mathrm{c}}\right) \pm 3.47$ & 7.380 & 0.008 & 0.060 \\
\hline
\end{tabular}

Notes: aOne-way between-groups ANCOVA with the respective pretest, the client's CFS score, and educational level being set as covariates in the analysis for the client's health outcomes (ie, EMS, TUG, MBI, Lawton's IADL, MMSE, and WHOQOL-BREF [HK]) and the pre-CSI, the caregiver's age, gender, and educational level being set as covariates in the analysis for the caregiver's health outcome (ie, CSI). 'Scores range from 0 to 20 with a higher score representing better mobility. 'Adjusted mean score.

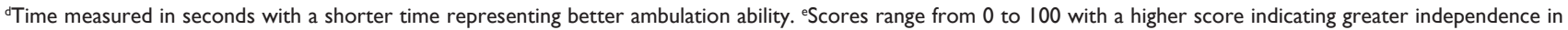
ADL. fScores range from 0 to 16 with a higher score representing greater independence in IADL. ${ }^{8}$ Scores range from 0 to 30 with a higher score indicating a better cognitive

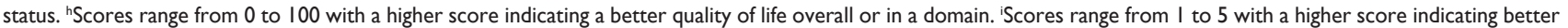
general quality of life/health. SScores range from 0 to 13 with a higher score representing a higher level of caregiving strain.

Abbreviations: EMS, Elderly Mobility Scale; TUG, Timed Up and Go; MBI, Modified Barthel Index; IADL, Instrumental Activities of Daily Living Scale; MMSE, Mini-Mental State Examination; QOL, quality of life; WHOQOL-BREF, World Health Organization Quality of Life Scale, Short Form; ADL, activities of daily living; CSI, Caregiver Strain Index; ANCOVA, analysis of covariance; CFS, Clinical Frailty Scale. 
Table 4 Comparisons of clients' changes in hospital services utilization between the intervention and matched-control groups

\begin{tabular}{|c|c|c|c|c|c|c|c|c|c|c|}
\hline \multirow[t]{2}{*}{ Outcomes } & \multicolumn{5}{|c|}{3 months before and after } & \multicolumn{5}{|c|}{6 months before and after } \\
\hline & $\begin{array}{l}\text { Intervention } \\
(\mathrm{N}=6 \mathrm{I})\end{array}$ & $\begin{array}{l}\text { Matched- } \\
\text { control }(\mathrm{N}=6 \mathrm{I})\end{array}$ & $F^{a}$ & $P$-value & $\begin{array}{l}\text { Partial } \\
\text { eta-square }\end{array}$ & $\begin{array}{l}\text { Intervention } \\
(\mathrm{N}=61)\end{array}$ & $\begin{array}{l}\text { Matched- } \\
\text { control }(\mathrm{N}=6 \mathrm{I})\end{array}$ & $F^{a}$ & $P$-value & $\begin{array}{l}\text { Partial } \\
\text { eta-square }\end{array}$ \\
\hline $\begin{array}{l}\text { Unplanned number } \\
\text { of AED attendances }\end{array}$ & $-0.66^{\circ} \pm 1.03$ & $0.05^{b} \pm 0.76$ & 11.054 & 0.001 & 0.086 & $-0.49 \div 0.96$ & $0.07^{c} \pm 0.68$ & 0.007 & 0.935 & $<0.001$ \\
\hline $\begin{array}{l}\text { Unplanned number } \\
\text { of hospital admissions }\end{array}$ & $-0.59^{b} \pm 0.92$ & $0.05^{b} \pm 0.43$ & 18.202 & $<0.001$ & 0.134 & $0.00^{\complement} \pm 0.82$ & $0.11 \subset \pm 0.52$ & 0.958 & 0.330 & 0.008 \\
\hline $\begin{array}{l}\text { Unplanned number } \\
\text { of hospital bed days }\end{array}$ & $-13.98^{b} \pm 18.28$ & $-0.33^{b} \pm 10.61$ & 17.817 & $<0.001$ & 0.131 & $-1.84^{c} \pm 13.07$ & $0.43^{c} \pm 6.02$ & 2.302 & 0.132 & 0.019 \\
\hline
\end{tabular}

Notes: Hospital services utilization. ${ }^{a}$ One-way between-groups ANCOVA with the client's CFS score and educational level being set as covariates in the analysis. ${ }^{\mathrm{b}} \mathrm{Changes}$ were calculated by subtracting the count of hospital service utilization outcomes 3 months before the HBRS from the count of the hospital service utilization outcomes 3 months after the HBRS. ${ }^{c}$ Changes were calculated by subtracting the count of hospital service utilization outcomes 6 months before the HBRS from the count of the hospital service utilization outcomes 6 months after the HBRS.

Abbreviations: HBRS, home-based rehabilitation service; CFS, Clinical Frailty Scale; AED, Accident and Emergency Department.

the present study showed that the clients' improvement in mobility was 3.87 points (24.2\%) as measured by the EMS. Hence, this study's HBRS demonstrated a significant positive clinical impact on the clients. Moreover, the positive result in the ability of ambulation (ie, TUG) was consistent with the results of mobility. The intervention group demonstrated an improvement in ambulatory ability by a reduction of 14.92 mean seconds in TUG. The intervention group also recorded a $16.0 \%$ improvement in terms of the physical activities of daily living (ie, MBI). These improvements can be considered clinically significant in reference to the MCID reference of $9.25 \%$ for MBI in stroke rehabilitation. ${ }^{38}$ In addition, a mean score of $>75$ in MBI also indicates that the clients' self-care ability has generally improved from a moderate to a mild dependency level..$^{39}$ The intervention group also reported an increase of $19.3 \%$ improvement in instrumental activities of daily living (ie, Lawton's IADL). Furthermore, the partial eta-square result from the model was 0.186 , thereby showing that HBRS has an impact on the clients' instrumental activities of daily living. ${ }^{22}$ The person-centered care approach of HBRS and adoption of the tailor-made treatment plan may relatively explain these encouraging improvements in the clients' mobility and physical functioning. The significance of tailor-made interventions in achieving better physical health outcomes is supported by previous studies on older people. ${ }^{40,41}$

With respect to other health outcome measures for the clients, the intervention group demonstrated a substantial improvement in cognitive functioning (ie, MMSE). ${ }^{22}$ The findings of the present study are consistent with those of previous home-based rehabilitation studies that also used cognitive status as an outcome measure among mild cognitively impaired or dementia patients. ${ }^{42,43}$ Improvement in clients' cognitive status is unsurprising because cognitive and memory training sessions were provided to HBRS clients based on their training needs. In addition, the occupational therapist and rehabilitation assistant of HBRS also taught caregivers how to conduct cognitive and memory training in a home-based environment. This enhancement of the caregivers' ability to conduct home-based cognitive training for clients may amplify the therapeutic effects. Significant improvements were also observed in all the measurement aspects of quality of life in the intervention group, including the physical, psychological, social, and environmental aspects. Hence, HBRS is potentially effective in improving the clients' quality of life. In contrast, a multicenter RCT of a home-based physical rehabilitation program for patients just after a critical illness could not demonstrate any significant result on the outcomes of the health-related quality of life. ${ }^{44}$ This inconsistency between the results on quality of life may be explained by the patients' subjective experience with a recent critical illness, thereby affecting the patients' self-evaluations toward quality of life.

Results of the hospital services utilization were significant for the short term (3 months), including the frequency of emergency room attendance, unplanned hospital admissions, and unplanned hospital bed days. These results were consistent with those of a previous study on home-based care service for frail elders with high readmission rate in Hong Kong. The previous study demonstrated a significant reduction in the number of unplanned hospital admissions $(-1.41 \pm 1.23$ to $-0.77 \pm 1.31 ; P=0.049)$. However, the results in the frequency of emergency room attendance and unplanned hospital bed days were insignificant in the follow-up after 3 months. ${ }^{45}$ With regard to the follow-up after 6 months, the results on hospital services utilization could not demonstrate any statistically significant difference. Such insignificance may be related to the fact that the majority of clients did not 
avail HBRS after 3 months. Moreover, the hospital services utilization after 3 months may be due to health conditions that were unrelated to the clients' rehabilitation.

The present findings of the caregivers' caregiving strain (ie, CSI score) in the follow-up after 3 months were similar to those of a previous study. ${ }^{15}$ However, the positive effect of HBRS in reducing caregiving strain was not proven in earlier studies. ${ }^{15-17}$ Education and training provided to the caregivers, as well as the networking and referral made by HBRS to promote the client's rehabilitation, may have contributed to the reduction of caregiving strain. Accordingly, providing support to caregivers is important to the clients' rehabilitation. Further improving the support to caregivers could be pursued in future studies. Recent studies have suggested that the caregivers' burden and strain may vary in different cultures or gender. A study on stroke survivors in China suggested that the caregivers' strain index only slightly decreased after 6 months owing to strong family attachment in the Chinese culture and the fact that the major stress was acquired from their strong family obligations. ${ }^{46}$ Another recent study also indicated that women acquired higher caregiving strain than men because the former may experience several other stressors, such as financial problems. ${ }^{47}$ Therefore, cultural backgrounds of the caregivers should be understood at different settings and proper support should be provided to them. A previous study showed that providing comprehensive and interactive educational workshops to caregivers, with a longer evaluation period of up to 12 months, could result in significant improvement. ${ }^{48}$

The present study did not completely achieve the total sample size because of the presence of unmatched dyads with the intervention group. The study period was also relatively short. Another limitation was the use of the wide range of years (eg, 10 years) for matching the age between the intervention and control group clients because of a possible variation of physiological status owing to age difference. Moreover, this study excluded clients who declined participation because of their unwillingness to pay USD10 per session for HBRS. Further studies could adopt a more rigorous study design (eg, $\mathrm{RCT}$ ) and a longer follow-up period to evaluate the service. At present, HBRS only involves occupational therapists and physiotherapists. Future studies could focus on the involvement of multidisciplinary healthcare providers in the service to enhance holistic care. An RCT showed that the involvement of qualified nurses and trained nursing students in transitional care programs effectively reduced readmissions. ${ }^{49}$ In addition, applying health care technology (eg, telemedicine) may facilitate the improvement of the care process, thereby enabling recovery. Apart from exercise training, the use of sensor monitoring may be considered in coaching and monitoring the recovery process of older people. ${ }^{50}$

\section{Conclusion}

The HBRS used in this study has demonstrated its positive impact on promoting clients' short-term health outcomes and reducing their hospital services utilization. The merits of HBRS include establishing networks with both hospitals and community services, adopting a therapist and client mutually agreed treatment plan, and the use of a case management approach. These advantages could be considered the way forward in community HBRS. Additional investigations on the involvement of multidisciplinary healthcare professionals or the use of health care technologies in HBRS are suggested.

\section{Disclosure}

The authors report no conflicts of interest in this work.

\section{References}

1. Stott DJ, Quinn TJ. Principles of rehabilitation of older people. Medicine. 2017;45(1):1-5.

2. Giné-Garriga M, Roqué-Fíguls M, Coll-Planas L, Sitjà-Rabert M, Salvà A. Physical exercise interventions for improving performance-based measures of physical function in community-dwelling, frail older adults: a systematic review and meta-analysis. Arch Phys Med Rehabil. 2014;95(4):753-769.

3. Boland L, Légaré F, Perez MM, et al. Impact of home care versus alternative locations of care on elder health outcomes: an overview of systematic reviews. BMC Geriatr. 2017;17(1):20.

4. Toles M, Colón-Emeric C, Naylor MD, Asafu-Adjei J, Hanson LC. Connect-home: transitional care of skilled nursing facility patients and their caregivers. J Am Geriatr Soc. 2017;65(10):2322-2328.

5. Lockwood KJ, Taylor NF, Boyd JN, Harding KE. Pre-discharge home visits by occupational therapists completed for patients following hip fracture. Aust Occup Ther J. 2017;64(1):41-48.

6. Mas MÀ, Inzitari M, Sabaté S, Santaeugènia SJ, Miralles R. Hospitalat-home Integrated Care Programme for the management of disabling health crises in older patients: comparison with bed-based intermediate care. Age Ageing. 2017;46(6):925-931.

7. Sahota O, Pulikottil-Jacob R, Marshall F, et al. The Community In-reach Rehabilitation and Care Transition (CIRACT) clinical and cost-effectiveness randomisation controlled trial in older people admitted to hospital as an acute medical emergency. Age Ageing. 2017;46(1):26-32.

8. Karlsson Å, Berggren M, Gustafson Y, Olofsson B, Lindelöf N, Stenvall M. Effects of geriatric interdisciplinary home rehabilitation on walking ability and length of hospital stay after hip fracture: a randomized controlled trial. J Am Med Dir Assoc. 2016;17(5):464.

9. Bongartz M, Kiss R, Ullrich P, Eckert T, Bauer J, Hauer K. Development of a home-based training program for post-ward geriatric rehabilitation patients with cognitive impairment: study protocol of a randomizedcontrolled trail. BMC Geriatr. 2017;17(1):214.

10. Bradford NK. Enhanced rehabilitation and care models for adults with dementia following hip fracture surgery. Orthop Nurs. 2016; 35(3):187-188. 
11. Stolee P, Lim SN, Wilson L, Glenny C. Inpatient versus home-based rehabilitation for older adults with musculoskeletal disorders: a systematic review. Clin Rehabil. 2012;26(5):387-402.

12. Ellis G, Whitehead MA, Robinson D, O’Neill D, Langhorne P. Comprehensive geriatric assessment for older adults admitted to hospital: meta-analysis of randomised controlled trials. BMJ. 2011; 343:d6553.

13. Oerkild B, Frederiksen M, Hansen JF, Prescott E. Home-based cardiac rehabilitation is an attractive alternative to no cardiac rehabilitation for elderly patients with coronary heart disease: results from a randomised clinical trial. BMJ Open. 2012;2(6):e001820.

14. Ytterberg C, Thorsén AM, Liljedahl M, Holmqvist LW, von Koch L. Changes in perceived health between one and five years after stroke: a randomized controlled trial of early supported discharge with continued rehabilitation at home versus conventional rehabilitation. J Neurol Sci. 2010;294(1-2):86-88.

15. Crotty M, Giles LC, Halbert J, Harding J, Miller M. Home versus day rehabilitation: a randomised controlled trial. Age Ageing. 2008;37(6): 628-633.

16. Anderson C, Rubenach S, Ni Mhurchu C, Clark M, Spencer C, Winsor A. Home or hospital for stroke rehabilitation? Results of a randomized controlled trial. Stroke. 2000;31(5):1024-1034.

17. Park SG, Oliver P, Pennington M, et al. Rehabilitation of older patients: day hospital compared with rehabilitation at home. A randomized controlled trial. Health Technol Assess. 2009;13(39):1-143.

18. Folstein MF. The Mini-Mental State Examination. In: Crook T, Ferris S, Bartus R, editors. Assessment in Geriatric Psychopharmacology. Vol 40. New Canaan: Mark Powley; 1983:812-851.

19. Geriatric Medicine Research Unit, Dalhousie University. Clinical Frailty Scale; 2012. Available from: http://geriatricresearch.medicine.dal.ca/ clinical_frailty_scale.htm. Accessed June 12, 2014.

20. Chan DC, Tsou HH, Chen CY, Chen CY. Validation of the ChineseCanadian study of health and aging clinical frailty scale (CSHA-CFS) telephone version. Arch Gerontol Geriatr. 2010;50(3):e74-e80.

21. Zidén L, Frändin K, Kreuter M. Home rehabilitation after hip fracture. A randomized controlled study on balance confidence, physical function and everyday activities. Clin Rehabil. 2008;22(12):1019-1033.

22. Cohen JW. Statistical Power Analysis for the Behavioral Sciences. 2nd ed. Hillsdale: Lawrence Erlbaum Associates; 1988

23. Smith R. Validation and reliability of the elderly mobility scale. Physiotherapy. 1994;80(11):744-747.

24. Yu MS, Chan CC, Tsim RK. Usefulness of the elderly mobility scale for classifying residential placements. Clin Rehabil. 2007;21(12): 1114-1120

25. Podsiadlo D, Richardson S. The timed "Up \& Go": a test of basic functional mobility for frail elderly persons. J Am Geriatr Soc. 1991;39(2): 142-148.

26. Norén AM, Bogren U, Bolin J, Stenström C. Balance assessment in patients with peripheral arthritis: applicability and reliability of some clinical assessments. Physiother Res Int . 2001;6(4):193-204.

27. Shah S. Modified Barthel index or Barthel index (expanded). In: Salek S, editor. Compendium of Quality of Life Instruments, Part II. Chichester: Wiley and Sons; 1998.

28. Leung SO, Chan CC, Shah S. Development of a Chinese version of the modified Barthel index - validity and reliability. Clin Rehabil. 2007; 21(10):912-922.

29. Tong AYC, Man DWK. The validation of the Hong Kong Chinese version of the Lawton instrumental activities of daily living scale for institutionalized elderly persons. OTJR. 2002;22(4):132-142.

30. Huang WF, Chen PY. Activities of daily living and instrumental activities of daily living. In: VWQ Lou, Boey KW, editors. Handbook of Measures for the Chinese Elderly. Hong Kong: Sau Po Centre on Ageing, The University of Hong Kong; 2008:39-43.

31. Chiu HF, Lee H, Chung W, Kwong P. Reliability and validity of the Cantonese version of mini-mental state examination - a preliminary study. Hong Kong J Psychiatry. 1994;4(2):25.
32. Leung KF, Wong WW, Tay MSM, Chu MML, Ng SSW, Ng S. Development and validation of the interview version of the Hong Kong Chinese WHOQOL-BREF. Qual Life Res. 2005;14(5):1413-1419.

33. Chan WC, Chan CL, Suen M. Validation of the Chinese version of the modified caregivers strain index among Hong Kong caregivers: an initiative of medical social workers. Health Soc Work. 2013; 38(4):214-221.

34. Holland AE, Mahal A, Hill CJ, et al. Home-based rehabilitation for COPD using minimal resources: a randomised, controlled equivalence trial. Thorax. 2017;72(1):57-65.

35. Kool J, Oesch P, Bachmann S. Predictors for living at home after geriatric inpatient rehabilitation: a prospective cohort study. $J$ Rehabil Med. 2017;49(2):185-190.

36. Donohue K, Hoevenaars R, Mceachern J, Zeman E, Mehta S. Homebased multidisciplinary rehabilitation following hip fracture surgery: what is the evidence? Rehabil Res Pract. 2013;2013:875968.

37. de Morton NA, Berlowitz DJ, Keating JL. A systematic review of mobility instruments and their measurement properties for older acute medical patients. Health Qual Life Outcomes. 2008;6:44.

38. Hsieh YW, Wang CH, Wu SC, Chen PC, Sheu CF, Hsieh CL. Establishing the minimal clinically important difference of the Barthel index in stroke patients. Neurorehabil Neural Repair. 2007;21(3):233-238.

39. Ministry of Health, Singapore. Manual for Providers of Community Rehabilitation Services; 2010. Available from: https://www.moh.gov. sg/content/dam/moh_web/Publications/Guidelines/Step\%20down $\% 20$ care/2010/Manual\%20for\%20Community\%20Rehabilitation $\% 20$ Provider\%20MOH\%20_Final.pdf. Accessed December 2, 2017.

40. Lee FI, Lee TD, So WK. Effects of a tailor-made exercise program on exercise adherence and health outcomes in patients with knee osteoarthritis: a mixed-methods pilot study. Clin Interv Aging. 2016; 11:1391-1402.

41. de Vos BC, Runhaar J, Bierma-Zeinstra SM. Effectiveness of a tailormade weight loss intervention in primary care. Eur J Nutr. 2014;53(1): 95-104.

42. Yuill N, Hollis V. A systematic review of cognitive stimulation therapy for older adults with mild to moderate dementia: an occupational therapy perspective. Occup Ther Int. 2011;18(4):163-186.

43. Kurz A, Pohl C, Ramsenthaler M, Sorg C. Cognitive rehabilitation in patients with mild cognitive impairment. Int J Geriatr Psychiatry. 2009;24(2):163-168.

44. Elliott D, Mckinley S, Alison J, et al. Health-related quality of life and physical recovery after a critical illness: a multi-centre randomised controlled trial of a home-based physical rehabilitation program. Crit Care. 2011;15(3):R142.

45. Leung DY, Lee DT, Lee IF, et al. The effect of a virtual ward program on emergency services utilization and quality of life in frail elderly patients after discharge: a pilot study. Clin Interv Aging. 2015;10:413-420.

46. Han Y, Liu Y, Zhang X, Tam W, Mao J, Lopez V. Chinese family caregivers of stroke survivors: determinants of caregiving burden within the first six months. J Clin Nurs. 2017;26(23-24):4558-4566.

47. Swinkels J, Tilburg TV, Verbakel E, Broese van Groenou M. Explaining the gender gap in the caregiving burden of partner caregivers. J Gerontol B Psychol Sci Soc Sci. Epub 2017 Apr 3.

48. Wong FK, Chow SK, Chan TM, Tam SK. Comparison of effects between home visits with telephone calls and telephone calls only for transitional discharge support: a randomised controlled trial. Age Ageing. 2014;43(1):91-97.

49. Pol MC, Ter Riet G, van Hartingsveldt M, Kröse B, de Rooij SE, Buurman BM. Effectiveness of sensor monitoring in an occupational therapy rehabilitation program for older individuals after hip fracture, the SO-HIP trial: study protocol of a three-arm stepped wedge cluster randomized trial. BMC Health Serv Res. 2017;17(1):3.

50. Lorig K, Ritter PL, Laurent DD, Yank V. Building better caregivers: a pragmatic 12-month trial of a community-based workshop for caregivers of cognitively impaired adults. J Appl Gerontol. Epub 2017 Nov 1. 
Clinical Interventions in Aging

\section{Publish your work in this journal}

Clinical Interventions in Aging is an international, peer-reviewed journal focusing on evidence-based reports on the value or lack thereof of treatments intended to prevent or delay the onset of maladaptive correlates of aging in human beings. This journal is indexed on PubMed Central, MedLine,

CAS, Scopus and the Elsevier Bibliographic databases. The manuscript management system is completely online and includes a very quick and fair peer-review system, which is all easy to use. Visit http://www.dovepress. $\mathrm{com} /$ testimonials.php to read real quotes from published authors.

Submit your manuscript here: http://www.dovepress.com/clinical-interventions-in-aging-journal 